\title{
Comparative Analysis of Maximum Power Point Tracking Controllers under Partial Shaded Conditions in a Photovoltaic System
}

\author{
R. Ramaprabha ${ }^{a}$ and S.P. Chitra*b \\ Department of Electrical and Electronics Engineering, SSN College of Engineering, Rajiv Gandhi Salai, Kalavakkam-603110, \\ Chennai, Tamilnadu, India.
}

Received 18 March 2014; accepted December 2014

\begin{abstract}
Mismatching effects due to partial shaded conditions are the major drawbacks existing in today's photovoltaic (PV) systems. These mismatch effects are greatly reduced in distributed PV system architecture where each panel is effectively decoupled from its neighboring panel. To obtain the optimal operation of the PV panels, maximum power point tracking (MPPT) techniques are used. In partial shaded conditions, detecting the maximum operating point is difficult as the characteristic curves are complex with multiple peaks. In this paper, a neural network control technique is employed for MPPT. Detailed analyses were carried out on MPPT controllers in centralized and distributed architecture under partial shaded environments. The efficiency of the MPPT controllers and the effectiveness of the proposed control technique under partial shaded environments was examined using MATLAB software. The results were validated through experimentation.
\end{abstract}

Keywords: Partial shaded PV system, Efficiency, Artificial neural network, Centralized controller, Distributed controller.

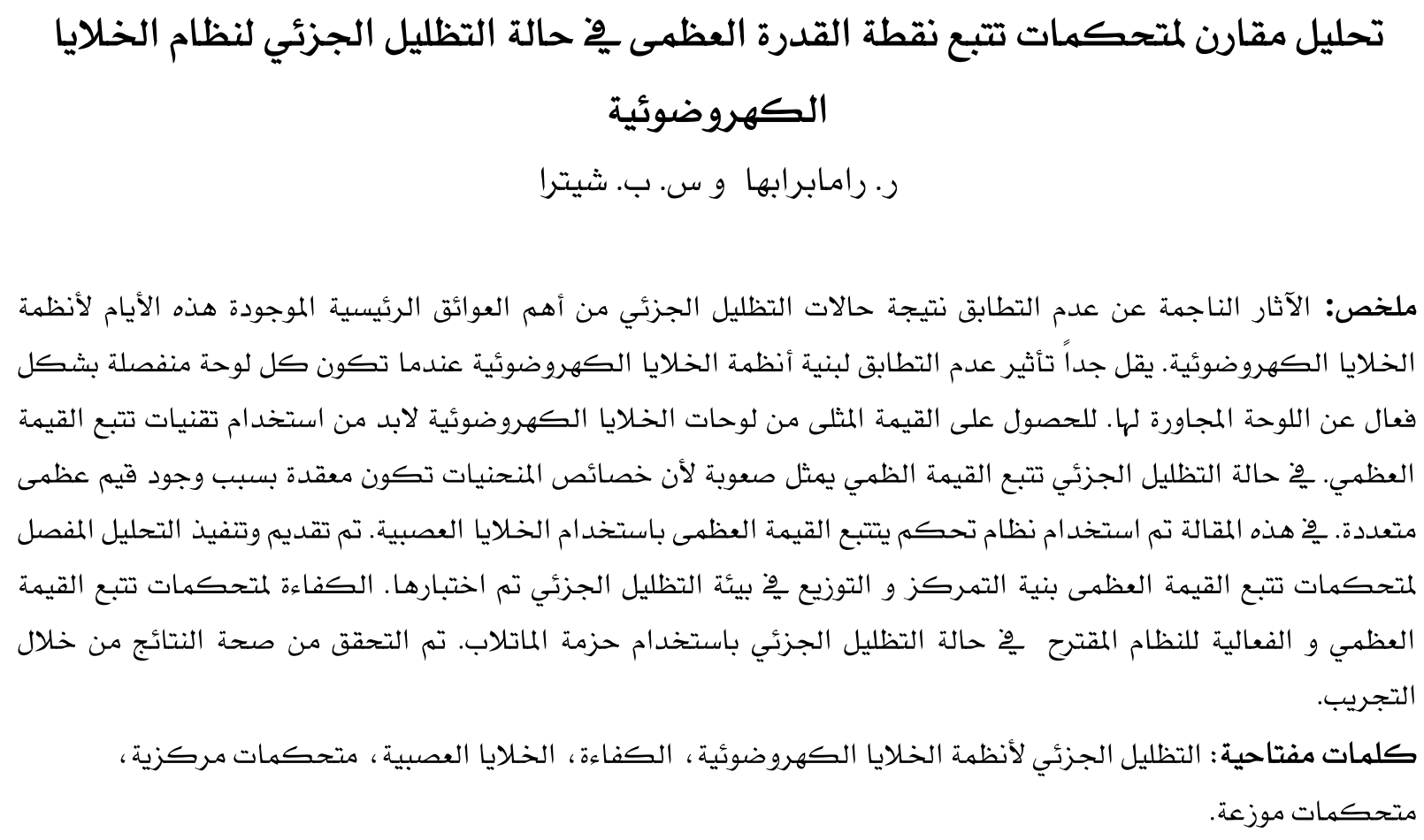

Corresponding author's email: chitraadk@gmail.com 


\section{Introduction}

Photovoltaic (PV) energy generation technology has been investigated intensively in the past decades due to continuously growing demands for renewable, environmentally friendly, and costefficient energy resources. At any given time and environmental condition, there is a single maximum power point (MPP) in PV panel characteristics. Maximum power point tracking (MPPT) is an electronic form of tracking that utilizes algorithms and control circuits to search for a maximum power point in a PV panel, thus allowing a converter circuit to harvest the maximum power available from a PV panel. Generally, the maximum power extracted from a PV panel depends on insolation conditions, load profile, and temperature. From the output and the V-I characteristics of commercial PV panels, it can be observed that the temperature changes mainly affect the PV output voltage while the irradiation/insolation levels affect the PV output current. MPP changes due to both sources of the variations (Masoum et al. 2002).

Basically, the MPPT algorithm can be classified as direct or indirect control. The indirect methods are based on the use of a database, where the parameters are calculated from the PV curves or by using mathematical functions. Even though they are simple and inexpensive, they are not versatile with respect to load profile. In contrast, the direct control measures either PV voltage or current. The optimum operating point is calculated by taking into account the variations of the operating point. In the current study, the operating point was independent of temperature, insolation, and degradation levels but the problems were the possibility of undesirable errors and difficulties with tracking accuracy. According to this basic principle, different methodologies, like differentiation, feedback voltage, perturb-and-observe, and incremental conductance, should be implemented. The efficiency and accuracy can still be improved by employing modern controllers using fuzzy logic or neural network (Walker 2001). MPPT in a uniformly illuminated condition is simple and easy to implement as there is a single optimum peak.

Nowadays there is an increasing trend toward using PV panels in urban rooftops or installing building integrated PV (BIPV) systems. In such applications, PV panels are mounted to outer-fit the roof/wall of the buildings. In these cases, different panels may receive different levels of insolation, which resembles conditions of partial shading. In partial shaded environments, to prevent panels being damaged by a hotspot (Koutroulis et al. 2001; Femia et al. 2005), antiparallel bypass diodes are used. This leads to the occurrence of multi-peaks in characteristics (Jain \& Agarwal, 2004; Patel \& Agarwal, 2008). To track the global peak, a complex MPPT is required; many researchers have been working in this area and have developed algorithms (Esram \& Chapman 2007; Silvestre et al. 2009; Herrmann et al. 1997).

Some researchers have addressed this problem by using distributed architecture where each panel has a separate converter (Walker \& Semia, 2004; Walker \& Pierce, 2006; Kasper et al. 2014). This increases the modularity, maximum power extracted, flexibility, and stability. In spite of the above advantages, the switching losses and converter costs are quite high when compared with centralized architecture where a single MPPT controller is employed.

This paper investigates the effectiveness and efficiency of MPPT controllers in distributed architecture and compares it with MPPT controllers in centralized architecture. The paper is organized as follows: section II deals with the effects of partial shading. Section III discusses the artificial neural network (ANN) control algorithm and its training methodology. Sections IV and V describe the MPPT controller in centralized and distributed architecture. Section VI presents the simulation results and their experimental verification. Section VII concludes with the comparative analysis of MPPT controllers and their suitability in specific applications.

\section{Effects of Partial Shading}

To understand the behavior of a solar cell, the equivalent circuit of the PV panel is derived based on discrete electrical components. A single diode model with five parameters is considered in this work (Ramaprabha \& Mathur, 2008; Karatepe et al. 2007; Villalva et al. 2009). This model offers a good compromise between simplicity and accuracy. The modeling equations are: 


$$
\begin{aligned}
& I_{P V}=I_{p h}-I_{D}-I_{s h} \\
& I_{P V}=I_{p h}-I_{r}\left[\exp \left\{\frac{V_{p v}+I_{p v} R_{s e}}{V_{t}}\right\}-1\right] \\
& -\frac{V_{p v}+I_{p v} R_{s e}}{R_{s h}} \\
& I_{p h}=\frac{G}{G_{\text {ref }}} \times I_{p h, \text { ref }}\left[1+\alpha\left(T-T_{\text {ref }}\right)\right] \\
& I_{r}=\frac{I_{\text {sc, ref }}+\alpha\left(T-T_{\text {ref }}\right)}{\exp \left\{\frac{V_{\text {oc, ref }}+\beta\left(T-T_{\text {ref }}\right)}{n V_{t}}\right\}-1}
\end{aligned}
$$

Generally, PV panels are connected in a series in order to achieve usable voltage. Partial shaded conditions is a critical issue in series-connected PV panels, because the shaded cells may get reverse biased and start consuming power instead of generating power. The resulting power loss in the shaded cells leads to local heating and creates thermal stress on neighboring panels. In a worst case scenario, the reverse bias across the shaded panels will exceed the breakdown voltage and get open circuited, and the entire array may be affected. In order to protect the panels, a bypass diode is connected across each panel, but these bypass diodes introduce multiple peaks in the characteristic curves, and it becomes essential to identify the global peak. In this paper, the effect of partial shaded conditions is analyzed and characteristic curves are obtained by considering a series of three connected panels along with a bypass diode (Fig. 1). The solar panel was modeled using 1-4 in a MATLAB m-file (MathWorks, Mattick, Massachusetts, USA). This can be extended to a number of solar panels $(\mathrm{m})$ in a series and number of solar panels (n) running in parallel (array size of $\mathrm{m} \times \mathrm{n}$ ) with a different shading pattern (Ramaprabha \& Mathur 2012). In this paper, a small PV array (size $3 \times 1)$ was considered (Fig. 1). The simulated characteristic curves were obtained for various insolation levels. The characteristic curve for ten different random shading profiles is shown in Fig. 2.

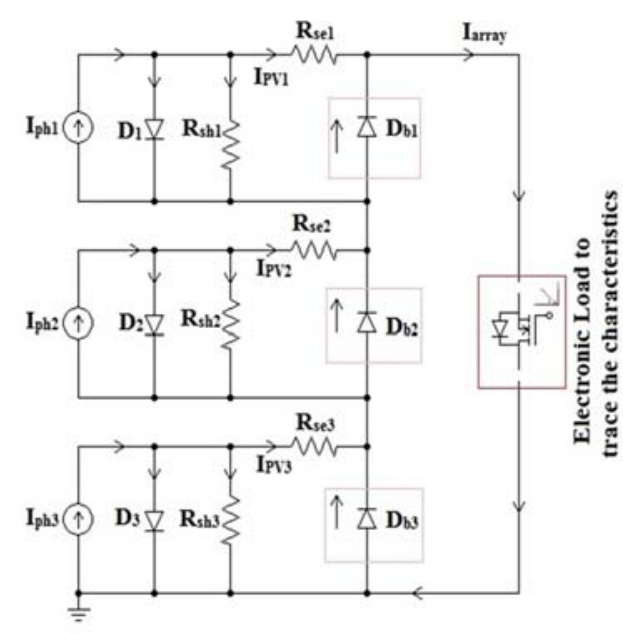

Figure 1. Electrical representation of three panels connected in a series with partial shading.

\section{Artificial Neural Network Controller}

There are a number of MPPT algorithms present in the literature, but in this paper, a neural network-based MPPT algorithm was used. Artificial neural networks (ANNs) are best suited to the approximation of non-linear systems. Nonlinear systems can be exactly emulated by multilevel neural networks, which yield better results than other algorithms (Torres 1998; AlAmoudi \& Zhang 2000; Hiyama \& Kitabayashi 1997; Aït Cheikh et al. 2007). Because of parallel computation of ANNs, the computation is fault tolerant (ie. deterioration of a few weights and/or missing links will not significantly deteriorate the output signal's quality). In addition, ANNs have noise or harmonic filtering properties. The most commonly used feed forward multilayer back propagation network was chosen for this work. The architecture of the ANNs for this work is shown in Fig. 3. The network is normally called a multilayer neural network and contains three layers: the input layer, the hidden layer, and the output layer. A neural network has to be configured such that the application of a set of inputs produces the desired set of outputs. Various methods to set the strengths of the connections exist. One way is to set the weights explicitly, using a priori knowledge. Another way is to train the neural network by feeding it 

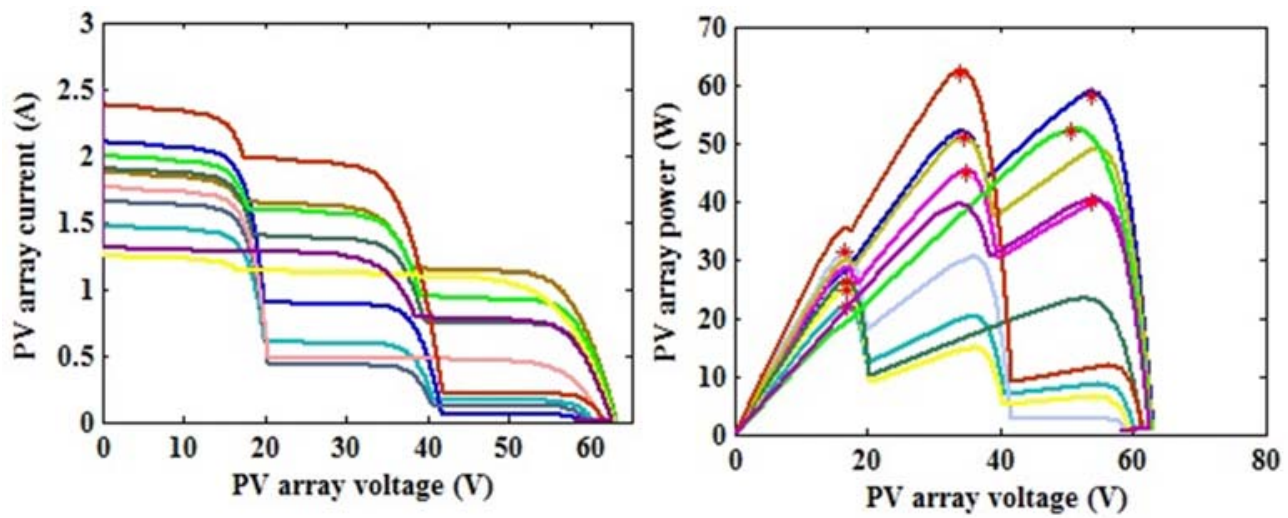

Figure 2. Characteristic curves with partial shaded conditions.

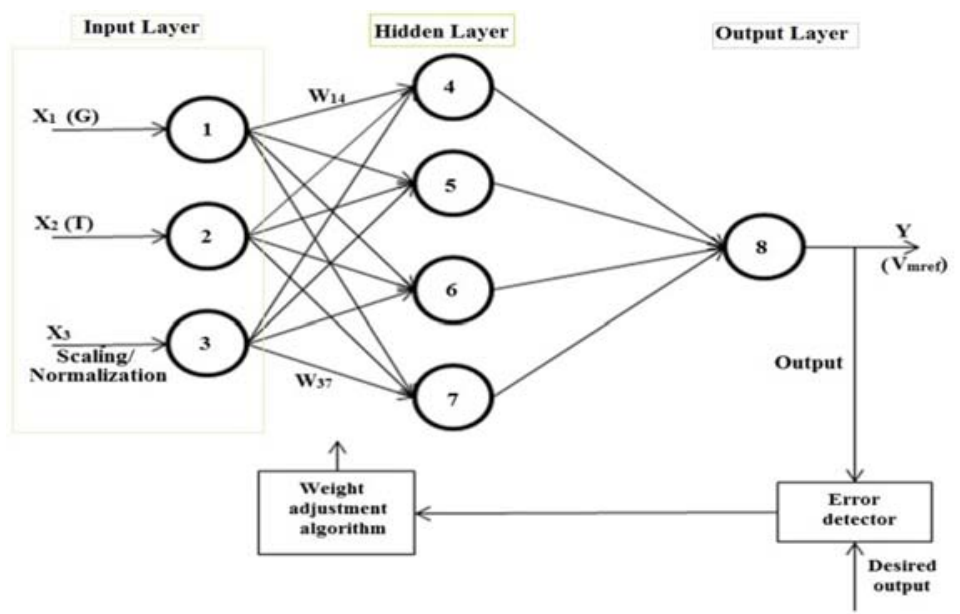

Figure 3. A multilayer feed forward neural network.

teaching patterns and letting it change its weights according to some learned rule.

In the present study, the neural network was first trained in the offline mode which was provided with two inputs: a temperature and an insolation pattern. The desired output, or MPP, was first calculated practically for a particular insolation and temperature. Temperature and insolation levels were measured with a thermocouple and a pyrometer. The data were stored in a memory module via a data logger (Model DWR 8102, Stack, Ltd., Bicester, UK). The experimental data for various insolation levels were computed by repeating the experiments in different weather conditions. The neural network was presented with different patterns of insolation and desired outputs for the corresponding pattern. Its weights were adjusted so as to provide the desired outputs. In this paper, ANNs were trained with 250 data points. The training results obtained for the ANN block using MATLAB are shown in Fig. 4.

At the end of the training, a feed forward multilayer back propagation ANN network incorporated in this work was trained to detect the MPP under various insolation's and temperatures. The maximum power extracted from the panel varied according to PV panels' ages and the accumulated thickness of dirt and dust. The incorporated ANN network can be trained to track performance degradation due to panels' aging and the amount of dirt and dust that is accumulated on the panels by feeding the network with a degradation factor. The degradation factor can be determined with the help of the 2012 National 


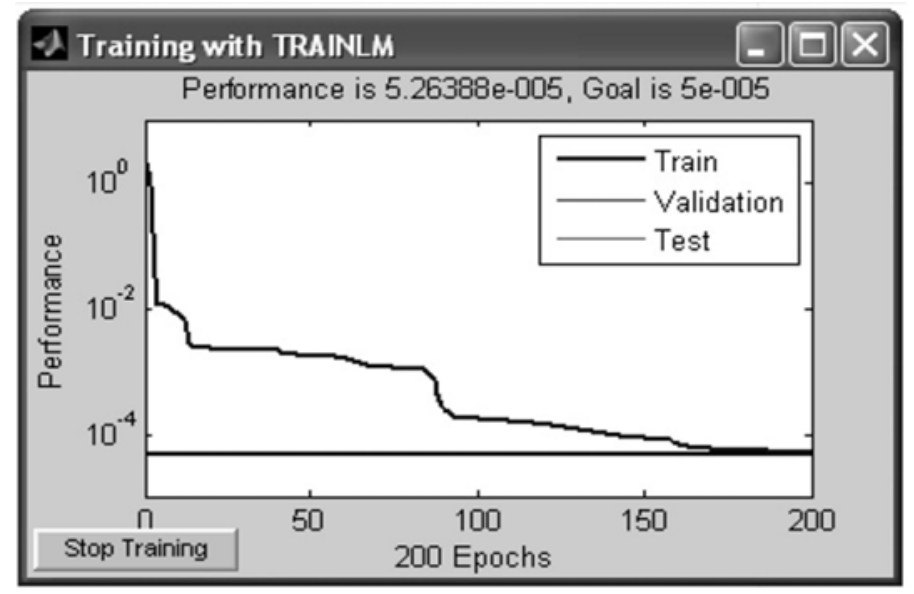

Figure 4. Training results of the artificial neural network (ANN).

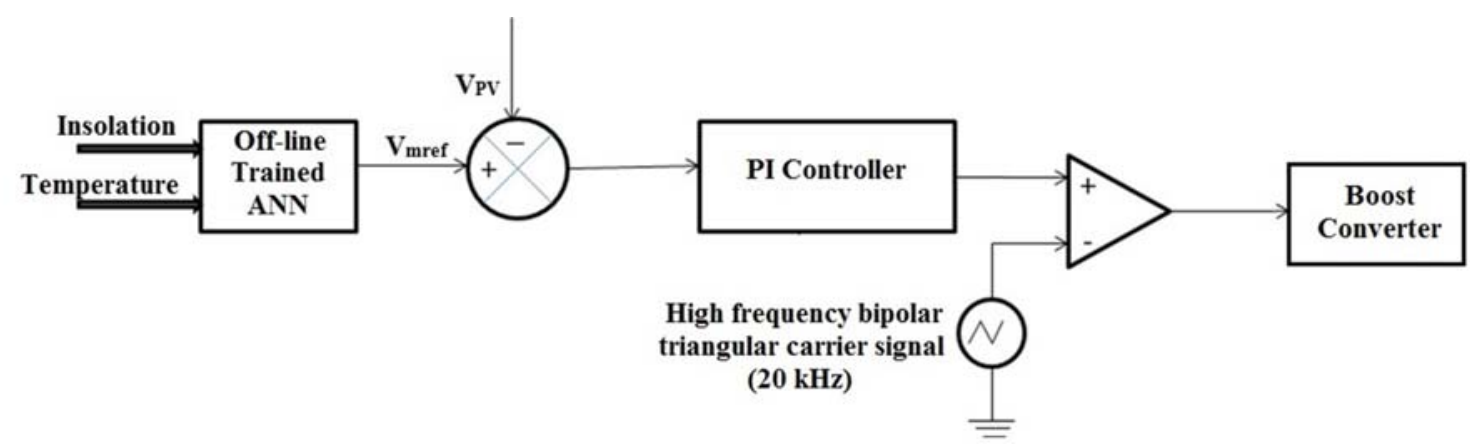

Figure 5. The artificial neural network (ANN) with maximum power point tracking (MPPT).

Renewable Energy Laboratory (NREL) report provided by Jordan and Kurtz. However a network might not be able to track performance variation due to panel damage as such a phenomenon is unpredictable.

The MPP of the PV panel was tracked using a simple boost converter as a power conditioning unit. The response was improved by incorporating a proper PI controller. The initial values of the integral and proportional constants $\left(\mathrm{K}_{\mathrm{p}}\right.$ and $\left.\mathrm{K}_{\mathrm{i}}\right)$ were determined using the Ziegler-Nichols method. Then the values were tuned to get the required response with the values of $K_{p}=0.0002$ and $K_{i}=125$, respectively. The controlled error was compared with a high frequency bipolar triangular carrier to produce pulse-width modulation (PWM) signals for the boost converter. The block diagram of ANN-based MPPT control used in this work is shown in Fig. 5.

\section{Maximum Power Point Tracking (MPPT) in a Centralized Configure- tion}

In a centralized configuration, the PV panels are connected in a series to a single power conditioning unit as in Fig. 6. In this type of configuration, multiple peaks are observed in the characteristics due to the presence of bypass diodes. Hence, it is required to identify the global peak. This can be achieved by the continuous scanning of characteristics. This approach to calculating the MPP is referred to as a scanned maximum power point tracking (SMPPT) system (Itako 2012). In a SMPPT, a single offline trained ANN controller is employed. The ANN controller is fed with $(2 \times n)$ inputs, where $n$ is the number of panels. The controller is trained to identify the global peak for any given set of temperatures and insolation values from the three solar panels. The ANN controller, along 


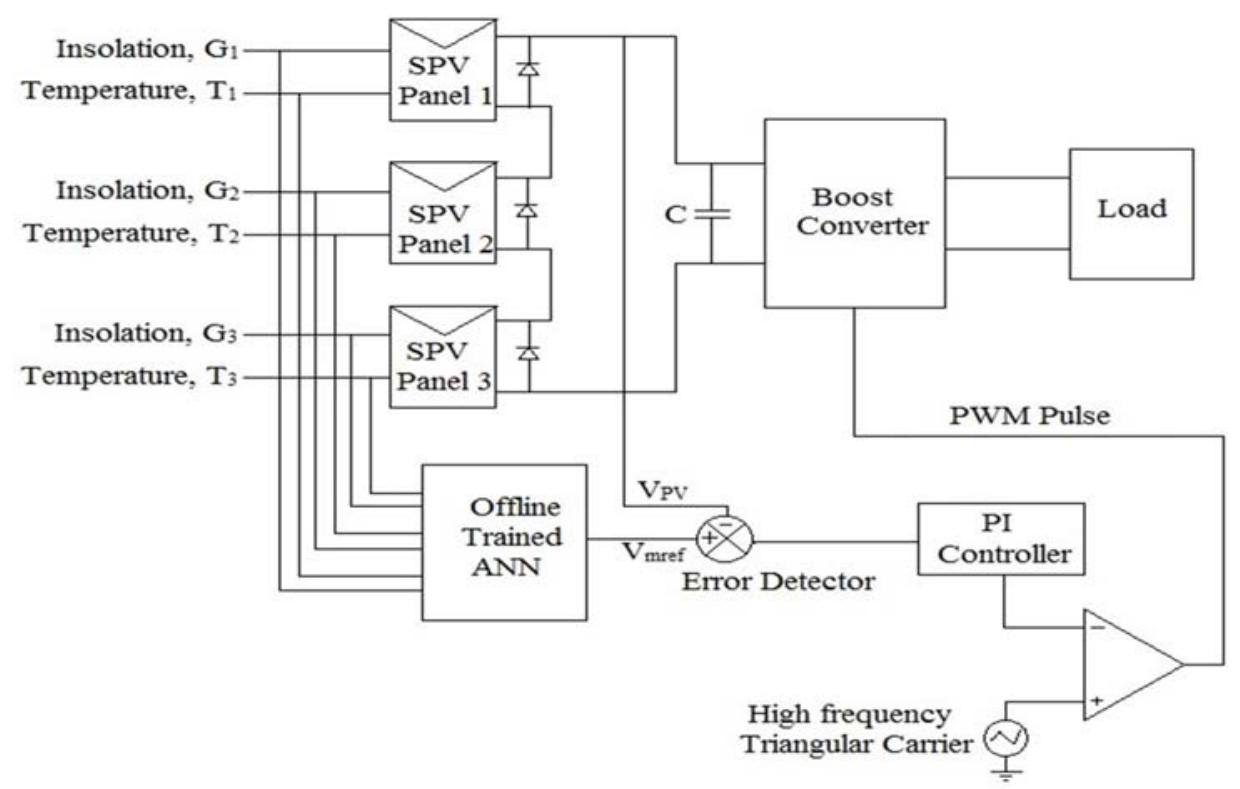

Figure 6. Maximum power point tracking (MPPT) in centralized architecture.

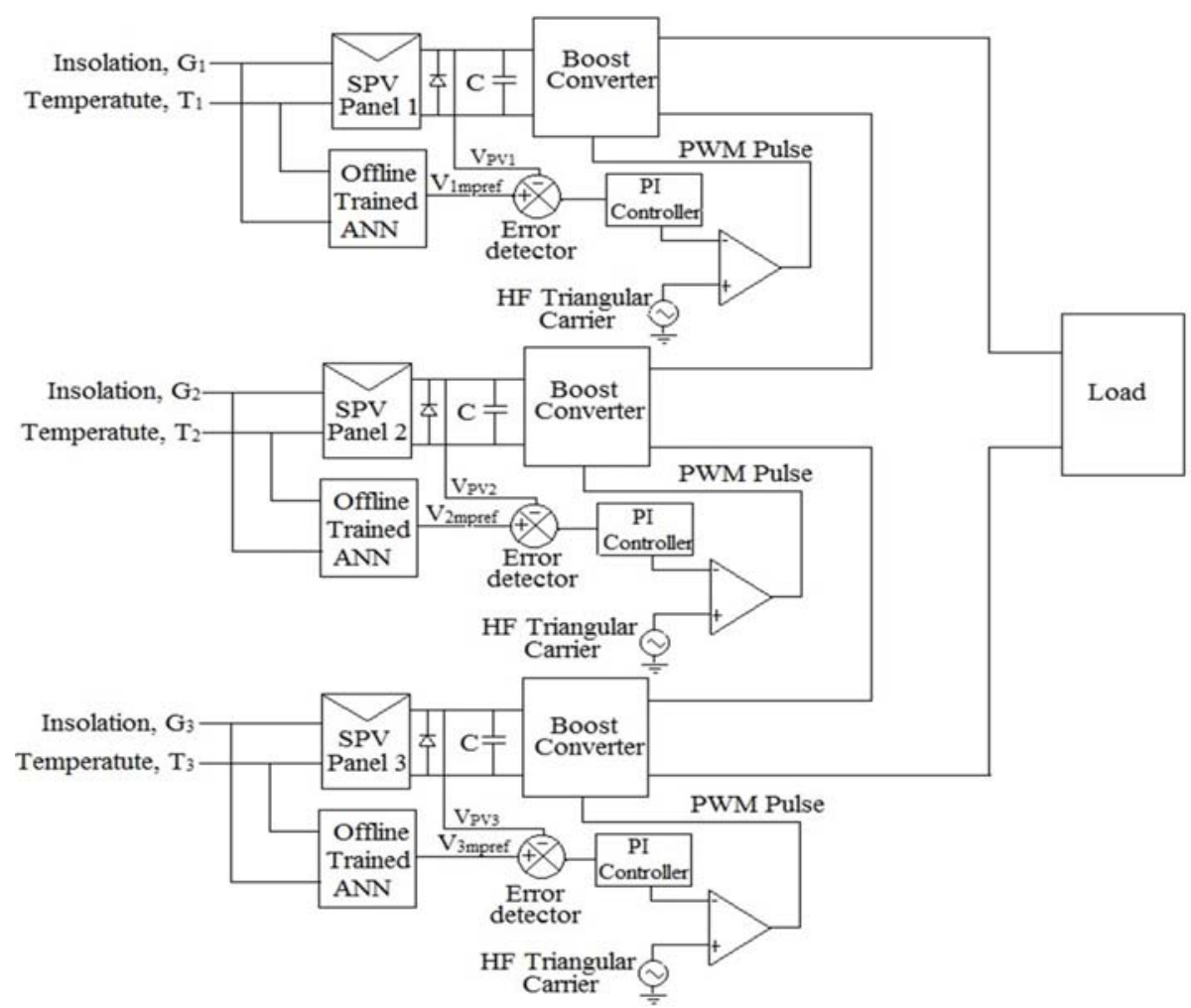

Figure 7. Maximum power point tracking (MPPT) in distributed architecture.

with the PI controller, provides pulses to the power conditioning unit such that the maximum possible power is extracted. The training algorithm is quite complex since it has to settle down at an optimum point. A centralized configuration results in disproportionate losses. This is due to the fact that MPPT in a centralized configuration becomes confused, stopping on a local maximum point and settling in a sub-optimal point of the voltage-topower configuration; second, the voltage point of 
the MPP can be very diverse due to irregular conditions, going beyond the scope and voltage range of the centralized MPPT.

\section{Maximum Power Point Tracking (MPPT) in a Distributed Configuration}

In the case of distributed architecture, each PV panel has separate power conditioning units and controllers, and the entire setup is connected in a series as in Fig. 7. In such a case, ANN controllers are employed to extract the maximum available power from a particular panel. Each controller has only two inputs and calculates the MPP corresponding to each panel. As the number of inputs lessens, training of an ANN controller becomes quite simple and fast.

This makes the system simpler, modular, and stable (Jiang et al. 2012) since the performance and control of one panel is effectively decoupled from the other. At the same time, there is no need to detect the global peak as in the case of centralized architecture. The control algorithm is also quite simple. Distributed MPPT can enhance and boost the performance of panels independently. One of the key advantages of having distributed plant architecture is the increased availability of a power plant, since a failure in a single direct current (dc)-dc converter or the disconnection or malfunction of a group of strings does not lead to a complete plant shutdown. Another important factor to be considered is the number of converters employed in distributed architecture and their cost factor. Moreover, the higher efficiency introduced in distributed architecture is greatly reduced by the static and dynamic losses of the power conditioning units as they are operated at a high switching frequency.

\section{Simulation Results}

In order to verify the performance of the ANNbased MPPT controller, a simulation was carried out on a three-series connected PV panel in the MATLAB environment. In each case, irradiance given to each panel was different from the neighboring panel. The Simulink model
(MathWorks, Mattick, Massachusetts, USA) used for the SMPPT is given in Fig. 8.

The temperature and insolation levels for the three panels were continuously sensed by the single-trained MPPT controller and provided the MPP for each pattern. The PWM technique was employed to vary the width of the pulse given to the power conditioning unit, such that it moved the operating point towards the MPP from each panel at any instant. The insolation patterns for study are shown in Table 1 . In pattern I, all of the panels were subjected to standard insolation and temperature to provide a base for comparison. Apart from that, random patterns were chosen such that

- Panel I was always subjected to standard insolation and temperature.

- Panel II was subjected to standard insolation with different temperature inputs to study the effect of temperature variation.

- Panel III was subjected to varied insolation and temperature patterns in order to study their combined effect on performance variation.

The input power extracted from the PV panels and the power delivered to the load is presented in Table 2. The simulated waveforms of the centralized architecture (Fig. 8) with a scanned MPPT controller for pattern V are shown in Fig. 9.

The MATLAB-Simulink model of an MPPT controller in a distributed environment is shown in Fig. 10. In order to facilitate comparison the same patterns of insolation levels are presented to PV panels. In this case, three separate offline trained MPPT controllers were employed to provide MPP for each panel. The maximum power from each panel was derived by separate power conditioning units using the PWM technique.

The input power extracted and output power delivered by individual panels in a distributed environment is given in Table 3.

The simulated waveforms of a PV panel with a DMPPT controller for pattern $\mathrm{V}$ are shown in Fig. 11. From the simulated waveforms, it can be inferred that a panel with an irradiance of 600 Watts $/ \mathrm{m}^{2}$ is being by passed. 


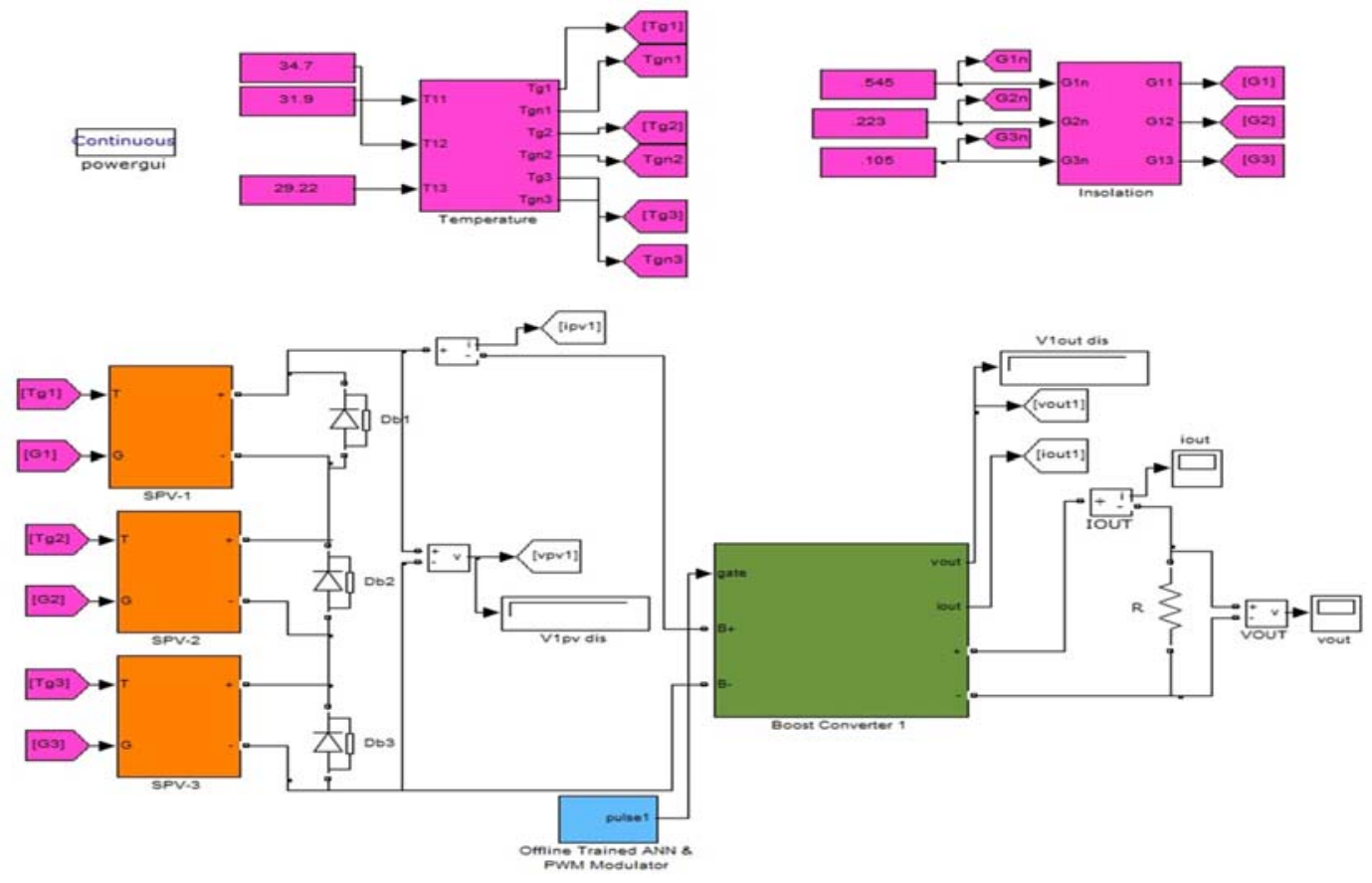

Figure 8. A Simulink model of centralized architecture.

Table 1. Patterns of insolation and temperature.

\begin{tabular}{ccccccc}
\hline \multirow{2}{*}{ Pattern } & \multicolumn{2}{c}{ Panel 1 } & \multicolumn{2}{c}{ Panel 2 } & \multicolumn{2}{c}{ Panel 3 } \\
\cline { 2 - 7 } & $\mathbf{G}_{\mathbf{1}}\left(\mathbf{W} / \mathbf{m}^{2}\right)$ & $\mathbf{T}_{\mathbf{1}}{ }^{\circ} \mathbf{C}$ & $\mathbf{G}_{\mathbf{2}}\left(\mathbf{W} / \mathbf{m}^{2}\right)$ & $\mathbf{T}{ }^{\mathbf{}} \mathbf{C}$ & $\mathbf{G}_{3}\left(\mathbf{W} / \mathbf{m}^{2}\right)$ & $\mathbf{T}{ }^{\circ} \mathbf{C}$ \\
\hline \hline I & 1000 & 25 & 1000 & 25 & 1000 & 25 \\
II & 1000 & 25 & 1000 & 38 & 1000 & 25 \\
III & 1000 & 25 & 1000 & 25 & 800 & 38 \\
IV & 1000 & 25 & 1000 & 31.9 & 800 & 38 \\
V & 1000 & 25 & 1000 & 35.9 & 1000 & 25 \\
\hline
\end{tabular}

Table 2. Input and output parameters in a scanned maximum power point tracking (SMPPT) system.

\begin{tabular}{ccccccc} 
& \multicolumn{3}{c}{ Input Parameters } & \multicolumn{3}{c}{ Output Parameters } \\
\cline { 2 - 7 } Pattern & $\mathbf{V}_{\mathbf{P V}}(\mathbf{V})$ & $\mathbf{I}_{\mathbf{P V}}(\mathbf{A})$ & $\mathbf{P}_{\mathbf{P V}}(\mathbf{W})$ & $\mathbf{V}_{\mathbf{o}}(\mathbf{V})$ & $\mathbf{I}_{\mathbf{o}}(\mathbf{A})$ & $\mathbf{P}_{\mathbf{o}}(\mathbf{W})$ \\
\hline \hline I & 48.77 & 2.287 & 111.53 & 63.40 & 1.732 & 109.80 \\
II & 43.24 & 2.019 & 87.30 & 56.21 & 1.519 & 85.38 \\
III & 42.06 & 1.965 & 82.65 & 54.67 & 1.481 & 80.97 \\
IV & 29.95 & 1.39 & 41.63 & 35.10 & 1.155 & 40.54 \\
V & 34.21 & 1.593 & 54.49 & 35.43 & 1.501 & 53.18 \\
\hline
\end{tabular}



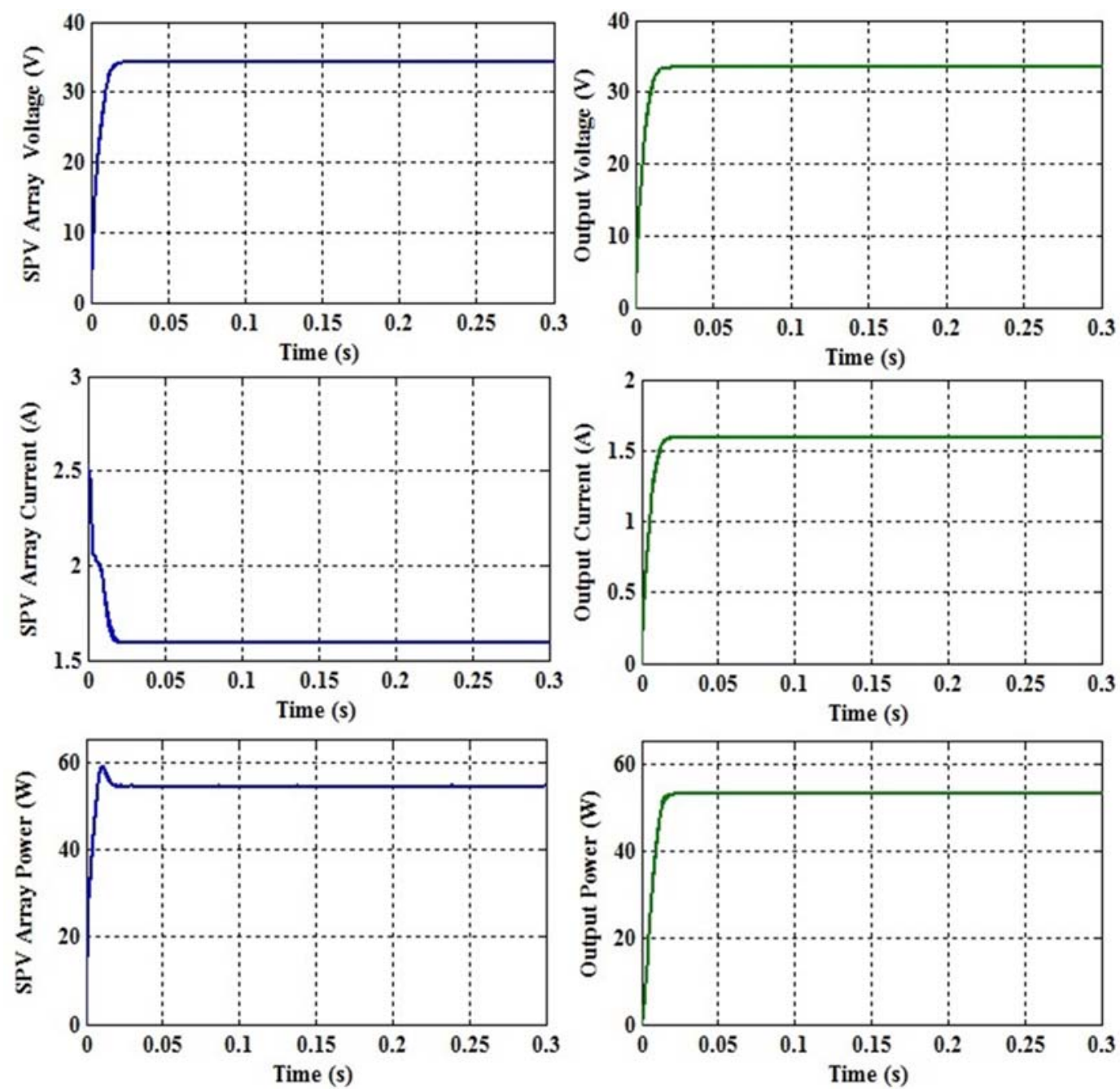

Figure 9. Input and output waveforms of a scanned maximum power point training (SMPPT) system for pattern V.

Table 3. Input and output parameters in distributed maximum power point tracking (DMPPT) systems.

\begin{tabular}{|c|c|c|c|c|c|c|c|c|}
\hline \multirow[b]{2}{*}{ Pattern } & \multicolumn{4}{|c|}{ Input side } & \multicolumn{4}{|c|}{ Output side } \\
\hline & $\begin{array}{c}\text { Input } \\
\text { power } 1 \\
\text { P PV1 }_{\text {PW) }}\end{array}$ & $\begin{array}{c}\text { Input } \\
\text { power } 2 \\
\text { P }_{\text {PV2 }}(W)\end{array}$ & $\begin{array}{c}\text { Input } \\
\text { power } 3 \\
\text { P }_{\mathrm{PV} 3}(\mathrm{~W})\end{array}$ & $\begin{array}{c}\text { Total } \\
\text { input power } \\
P_{P V}(W)\end{array}$ & $\begin{array}{l}\text { Output } \\
\text { power } 1 \\
\mathrm{P}_{\mathrm{o} 1}(\mathrm{~W})\end{array}$ & $\begin{array}{c}\text { Output } \\
\text { power } 2 \\
\mathrm{P}_{\mathrm{o} 2}(\mathrm{~W})\end{array}$ & $\begin{array}{l}\text { Output } \\
\text { power } 3 \\
\mathrm{P}_{\text {o3 }}(\mathrm{W})\end{array}$ & $\begin{array}{l}\text { Total } \\
\text { output } \\
\text { power } \\
\mathrm{P}_{\mathrm{o}}(\mathrm{W}) \\
\end{array}$ \\
\hline I & 37.3 & 37.2 & 37.3 & 111.8 & 35.41 & 35.70 & 35.44 & 106.55 \\
\hline II & 35.8 & 18.1 & 35.8 & 89.70 & 34.12 & 16.34 & 34.12 & 84.58 \\
\hline III & 24.6 & 35.0 & 24.6 & 84.20 & 23.14 & 33.52 & 23.14 & 79.80 \\
\hline IV & 19.6 & 1.1 & 23.1 & 43.80 & 18.51 & 0.04 & 21.98 & 40.53 \\
\hline $\mathrm{V}$ & 25.3 & 1.26 & 29.7 & 56.26 & 24.06 & 0.06 & 28.42 & 52.54 \\
\hline
\end{tabular}




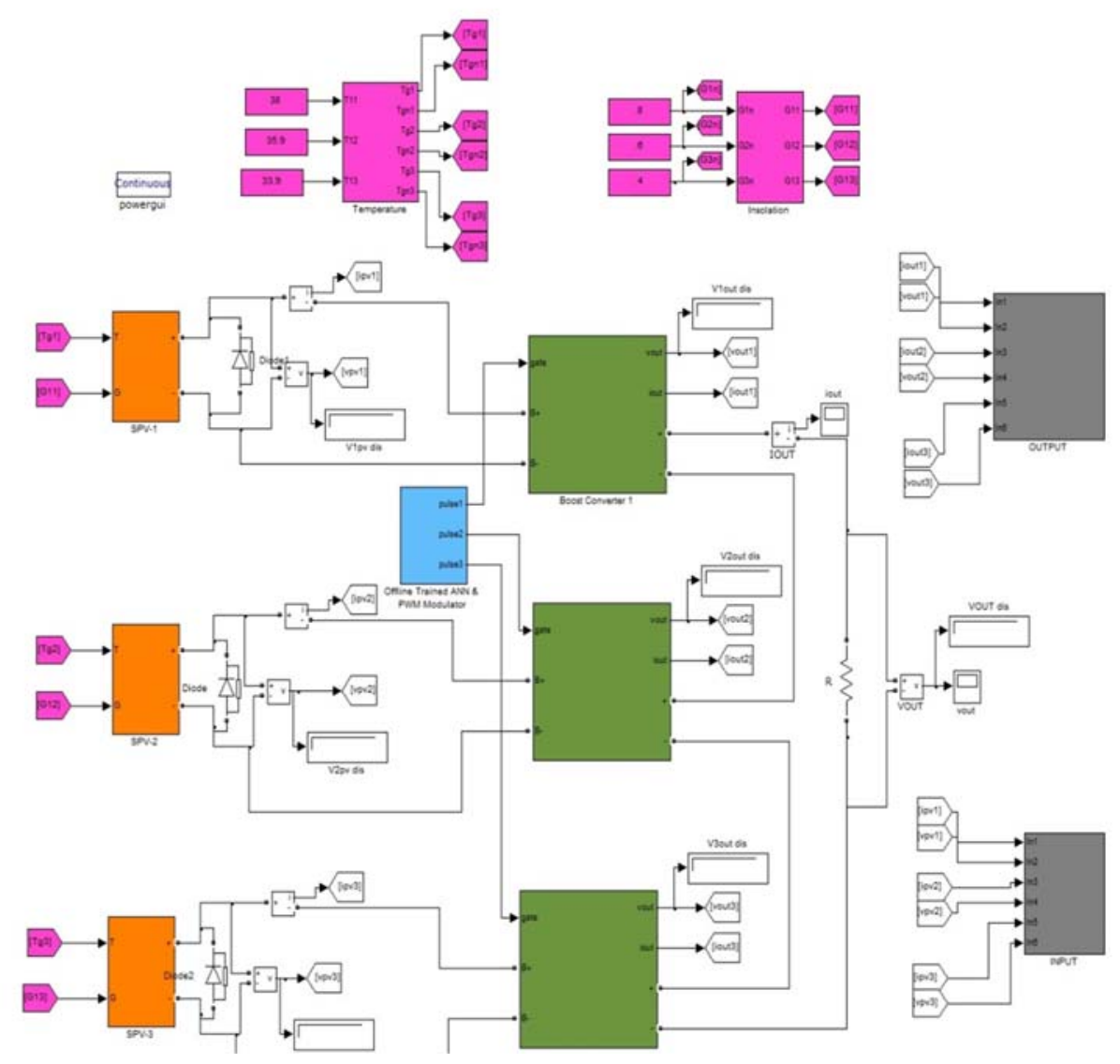

Figure 10. Simulink model of distributed architecture.

Table 4. Efficiency comparison in a simulated environment.

\begin{tabular}{ccc}
\hline Pattern & $\begin{array}{c}\boldsymbol{\eta} \text { in centralized } \\
\text { architecture (\%) }\end{array}$ & $\begin{array}{c}\boldsymbol{\eta} \text { in distributed } \\
\text { architecture (\%) }\end{array}$ \\
\hline \hline I & 98.45 & 95.30 \\
II & 97.80 & 94.29 \\
III & 97.97 & 94.77 \\
IV & 97.38 & 92.53 \\
V & 97.59 & 93.39 \\
\hline
\end{tabular}

Table 5. Devices used for hardware implementation.

\begin{tabular}{cc}
\hline Devices/Components & Specification/values \\
\hline \hline Switches & IRFP450 \\
Diode & IN5408 \\
Inductor(E-core) & $160 \mu \mathrm{H}, 200 \mu \mathrm{H}$ \\
Filter capacitors & $330 \mu \mathrm{F}, 220 \mu \mathrm{F}$ \\
Frequency & $20 \mathrm{kHz}$ \\
\hline
\end{tabular}



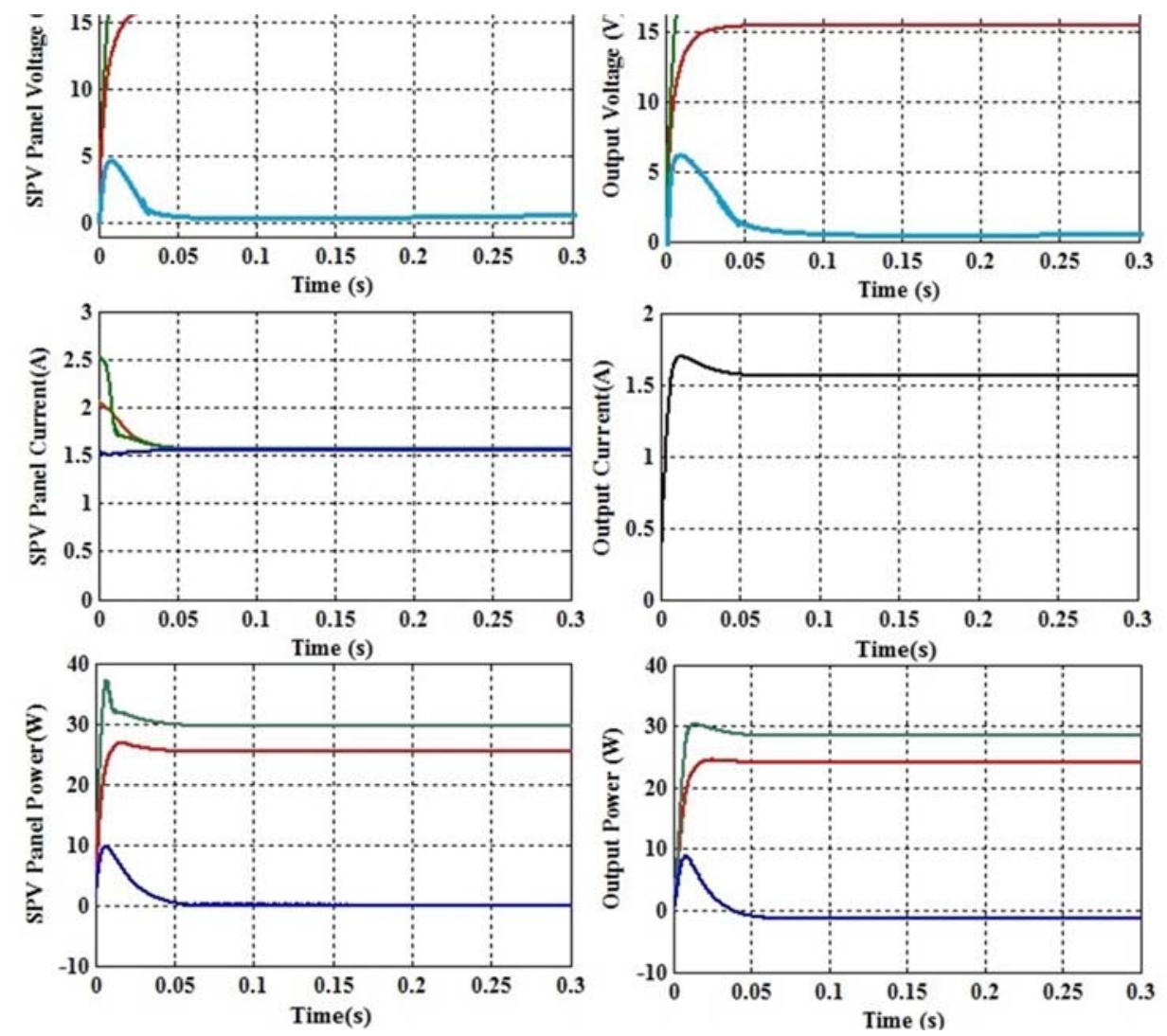

Figure 11. Input and output waveforms of distributed maximum power point tracking (DMPPT) for pattern V.

The efficiency of the MPPT controller in both centralized and distributed configurations was calculated with data obtained from simulations and was then compared for different patterns. The results were tabulated and are presented in Table 4. It can be observed that the power conversion efficiency of a SMPPT was around $4 \%$ greater than that of the DMPPT.

\section{Experimental Verification}

To verify the simulation results and to observe the characteristics of the MPPT controller practically, a series string system was built. The string system was comprised of three $37.08 \mathrm{~W}_{\mathrm{p}} \mathrm{PV}$ panels (Solkar Solar Industry Limited, Chennai, Tamil Nadu, India). The control algorithm was implemented with a digital signal processor (DSP) controller TMS320LF2407 (Texas Instruments, Inc., Houston, Texas, USA) and an opto-coupler transistor circuit for isolation. A step down transformer and an integrated circuit (IC) regulator 7812 was used to supply power to the controller circuit. The pulses from the controller were given to the power conditioning unit. Temperature and insolation levels were measured with a thermocouple and pyrometer via a Stack data logger (Model DWR 8102). The key system components used for hardware implementation are listed in Table 5.

The control scheme used in the hardware is shown in Fig. 12. Figure 13 shows the hardware set up of a SMPPT system, and Fig. 14 displays the control circuit implemented for a SMPPT system. Figure 15 shows the I-V curve for a $3 \times 1$ PV array with and without shading. The multiple steps in V-I characteristics lead to multiple peaks in V-P characteristics which are clearly identified in a partial shaded system. The shading is introduced artificially by covering part of the PV panels. 


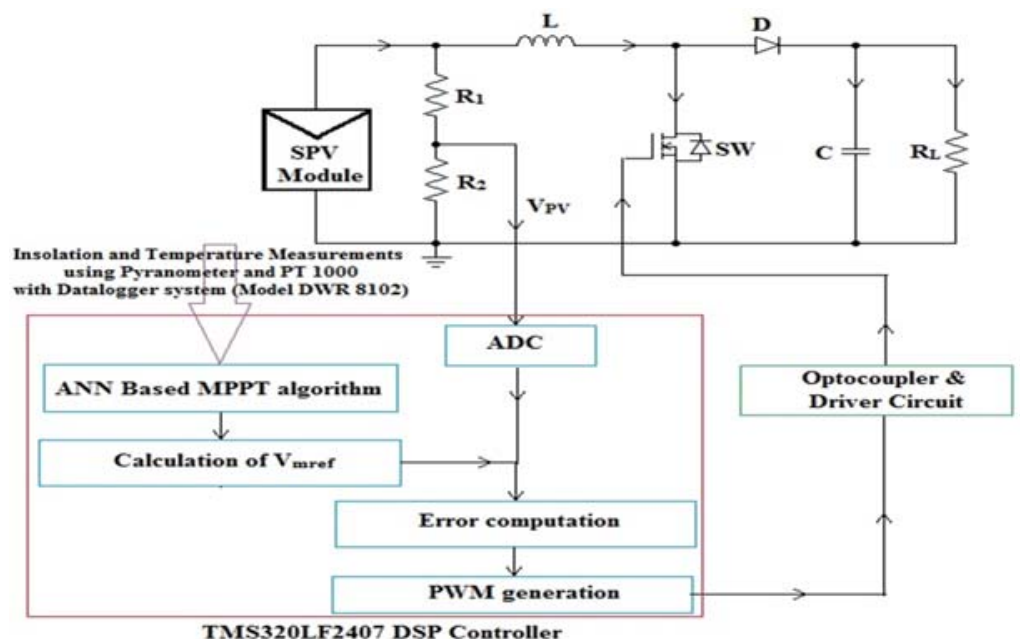

Figure 12. The control scheme of the hardware implemented.

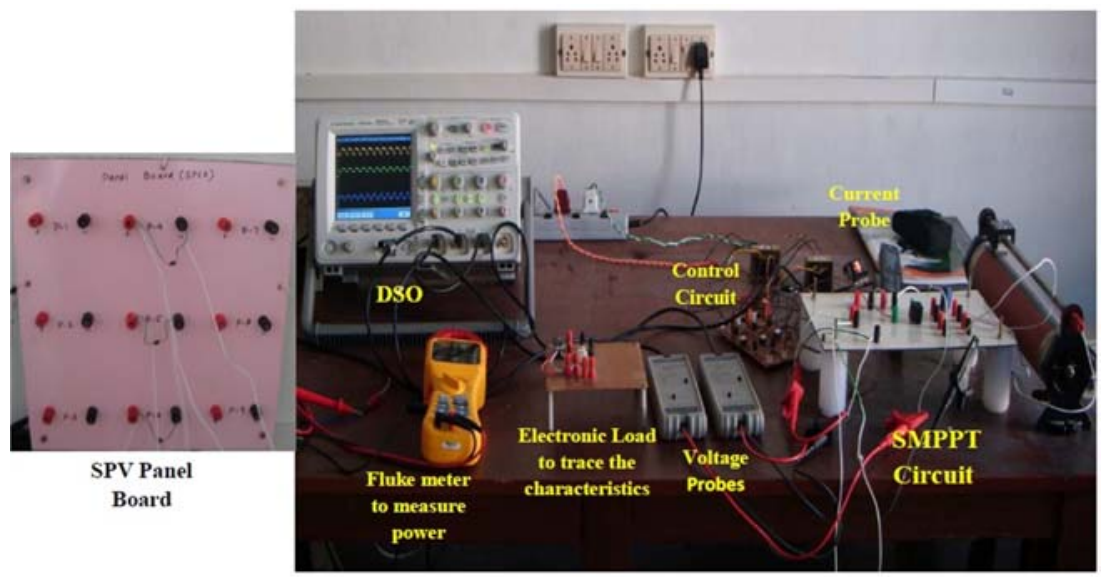

Figure 13. Hardware setup of a scanned maximum power point training (SMPPT) system.

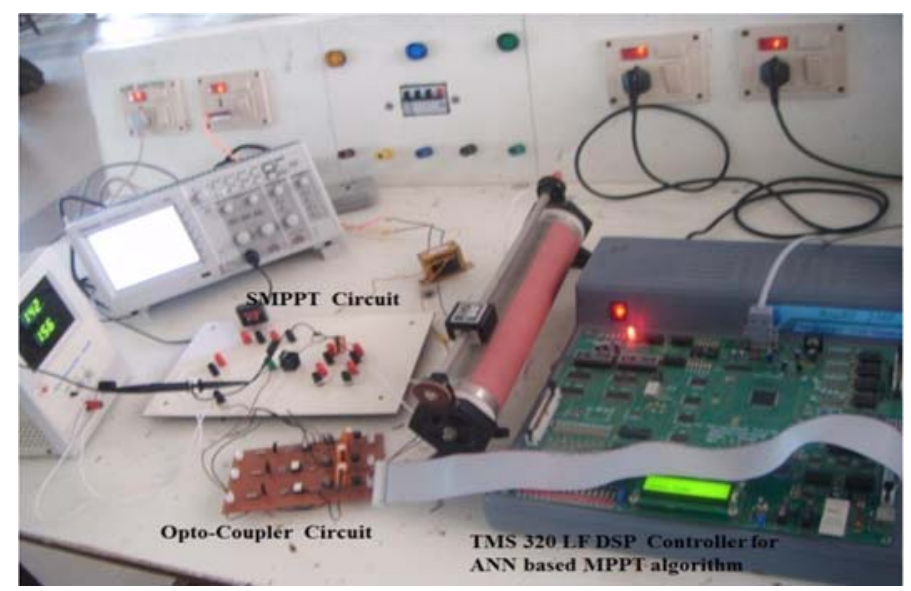

Figure 14. Control circuit of a scanned maximum power point training (SMPPT) system. 

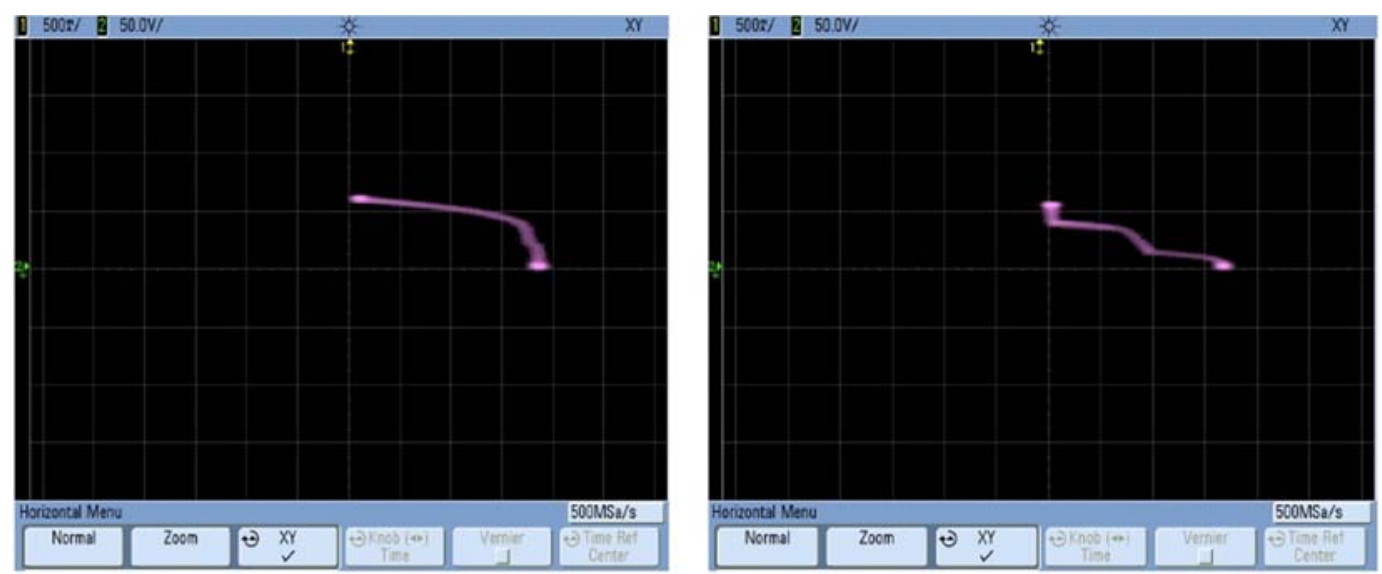

Figure 15. I-V curve with uniform illumination and non-uniform illumination.
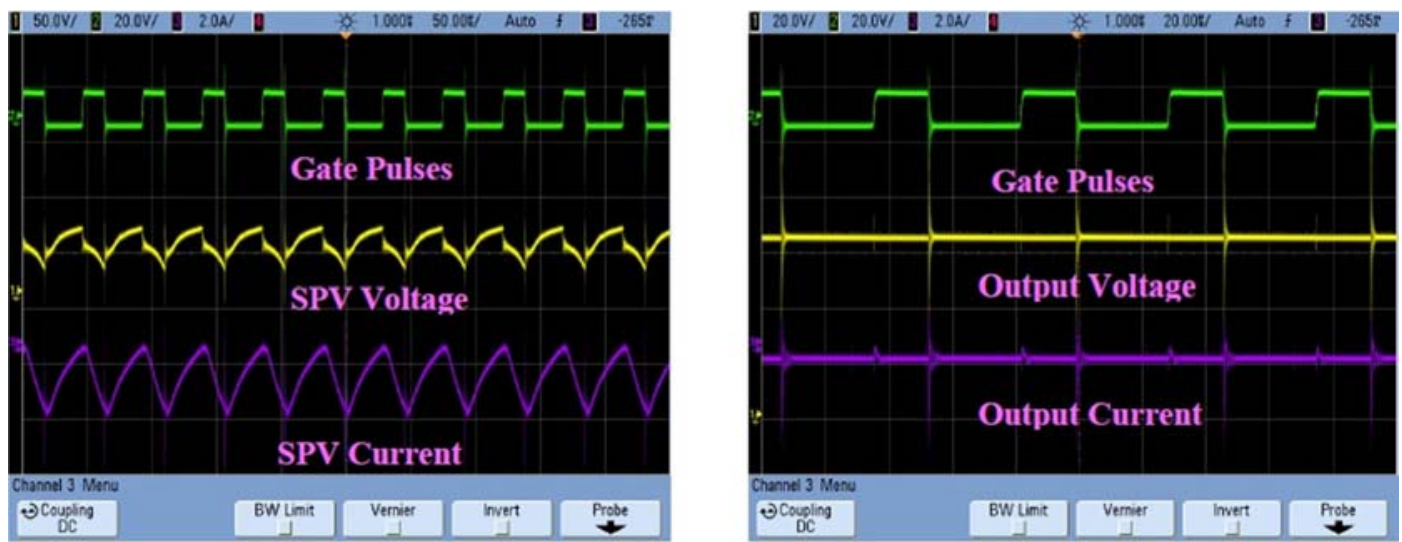

Figure 16. Voltage and current waveforms in a scanned maximum power point training (SMPPT) system without shading.
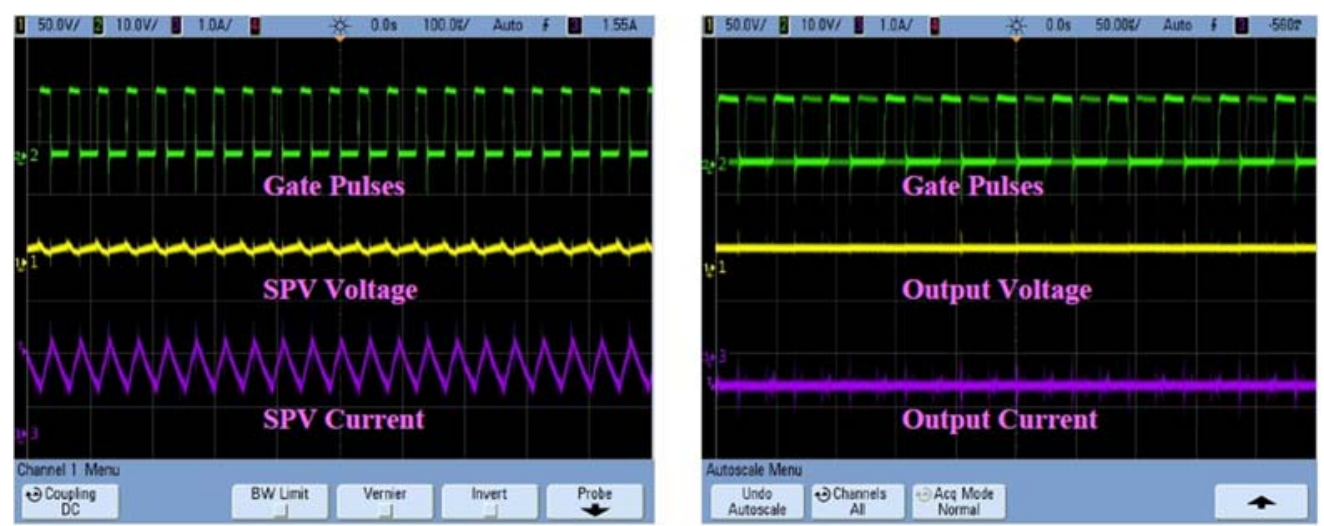

Figure 17. Voltage and current waveforms in a scanned maximum power point training (SMPPT) system with partial shading.

Figure 16 shows the waveforms for input PV voltage, PV current, output voltage, and output current with uniform insolation of $G=978 \mathrm{~W} / \mathrm{m}^{2}$ and $\mathrm{T}=31^{\circ} \mathrm{C}$. The parameters observed were as follows: $\mathrm{V}_{\mathrm{PV}}=48.8 \mathrm{~V} ; \mathrm{I}_{\mathrm{PV}}=2.2 \mathrm{~A} ; \mathrm{P}_{\mathrm{PV}}=107.36 \mathrm{~W} ; \mathrm{V}_{\mathrm{o}}$ $=68.01 \mathrm{~V} ; \mathrm{I}_{\mathrm{o}}=1.54 \mathrm{~A} ; \mathrm{P}_{\mathrm{o}}=104.73 \mathrm{~W}$. Figure 17 shows the waveforms of input PV voltage, PV current, output voltage, and output current with 
partial shaded conditions in a SMPPT System. Artificial shading was made by covering part of the two panels while one panel was allowed to receive the full insolation level. Upon coverage, the conditions were, $\mathrm{G}_{1}=978 \mathrm{~W} / \mathrm{m}^{2} ; \mathrm{G}_{2}=$ $682 \mathrm{~W} / \mathrm{m}^{2} ; \mathrm{G}_{3}=682 \mathrm{~W} / \mathrm{m}^{2}$ and $\mathrm{T}=31^{\circ} \mathrm{C}$. The parameters observed were as follows: $\mathrm{V}_{\mathrm{PV}}=49.29$ $\mathrm{V} ; \mathrm{I}_{\mathrm{PV}}=1.57 \mathrm{~A} ; \mathrm{P}_{\mathrm{PV}}=77.38 \mathrm{~W} ; \mathrm{V}_{\mathrm{o}}=68.69 \mathrm{~V} ; \mathrm{I}_{\mathrm{o}}=1.07$ $\mathrm{A} ; \mathrm{P}_{\mathrm{o}}=73.49 \mathrm{~W}$, and the power conversion efficiency was $\eta=94.97 \%$.

To compare the performance of centralized and distributed structures, the same shading pattern was retained and the parameters or variables were observed using the hardware set up of the DMPPT system, with three separate power conditioning units (Fig. 18). Figure 19 shows the waveforms of input PV voltage, PV current, output voltage and output current with partial shaded conditions in the DMPPT system. The values observed were $\mathrm{V}_{\mathrm{PV}}=49.01 \mathrm{~V} ; \mathrm{I}_{\mathrm{PV}}=1.55 \mathrm{~A} ; \mathrm{P}_{\mathrm{PV}}=$ $75.97 \mathrm{~W} ; \mathrm{V}_{\mathrm{o}}=68.53 \mathrm{~V} ; \mathrm{I}_{\mathrm{o}}=1.01 \mathrm{~A} ; \mathrm{P}_{\mathrm{o}}=69.20 \mathrm{~W}$, and $\eta=91.08 \%$.

Figure 20 exhibits the variation of the width of the control pulses produced by the DSP processor for different insolation levels and temperatures.

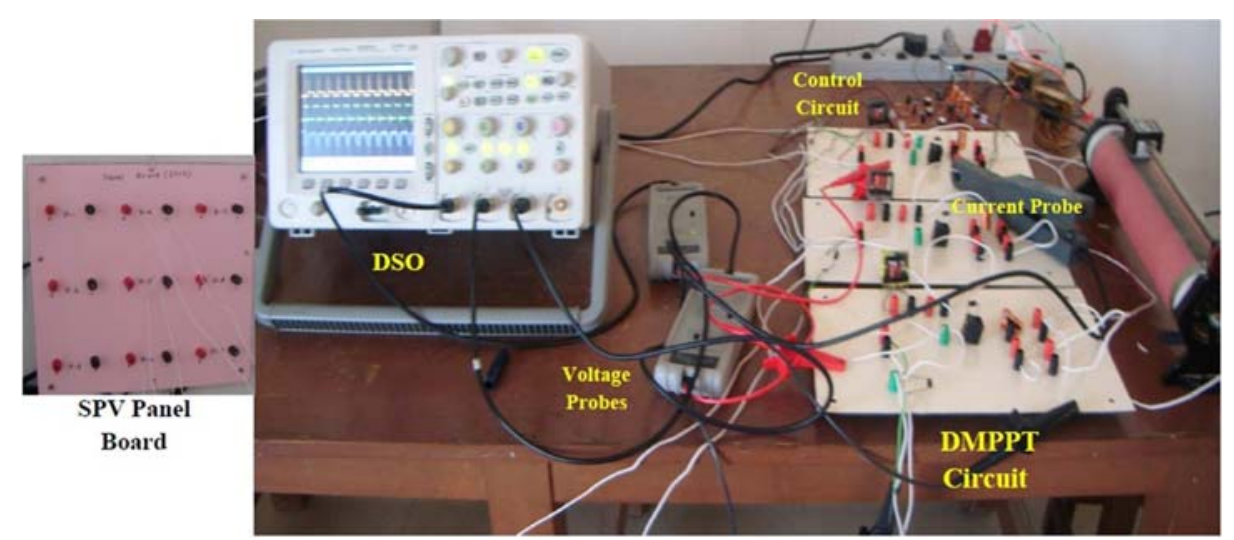

Figure 18. Hardware setup of the distributed maximum power point tracking (DMPPT) system.
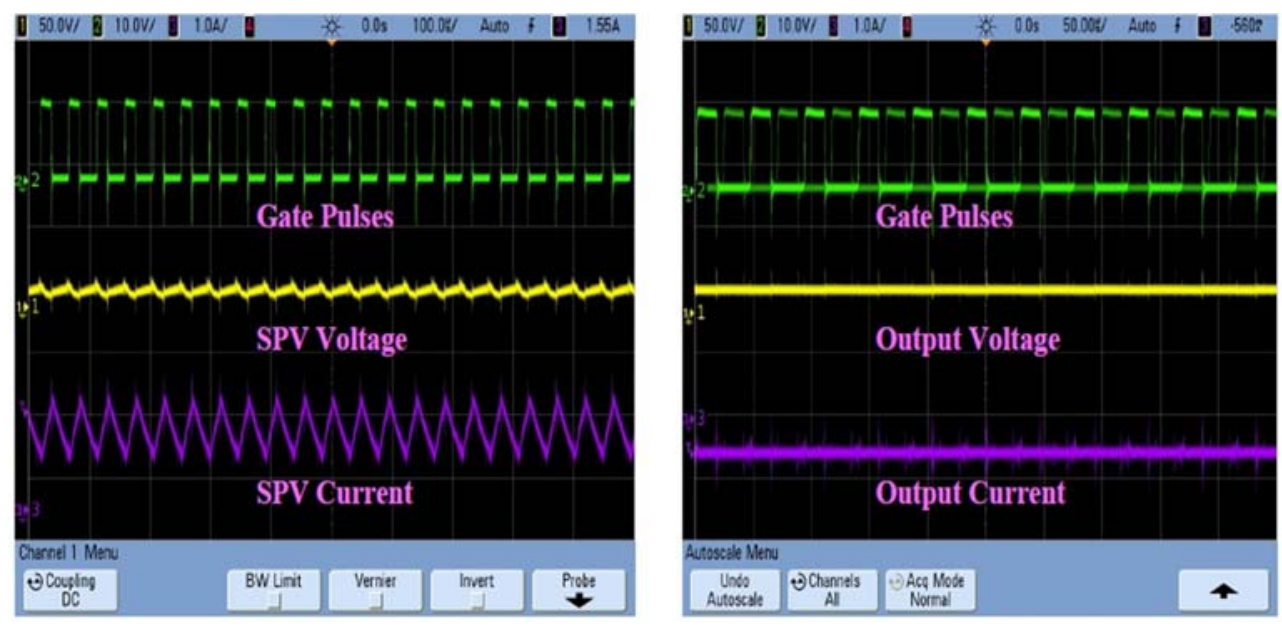

Figure 19. Input and output waveforms in the distributed maximum power point tracking (DMPPT) system. 

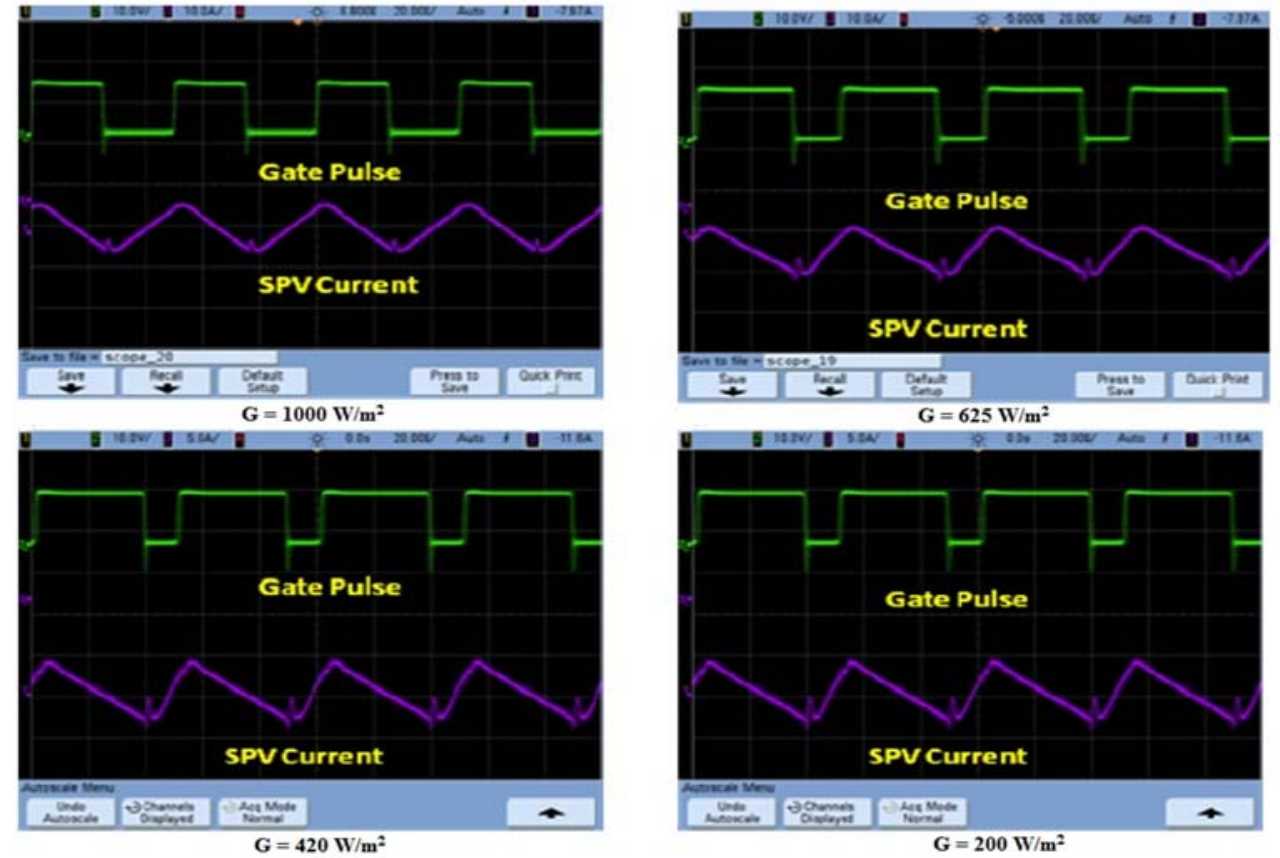

Figure 20. Pulse width variation for different insolations and temperatures.

Table 6. Comparison of maximum power point tracking (MPPT) controllers.

\begin{tabular}{c|c|c|c|c|c|c|c|c}
\hline \multicolumn{3}{c|}{$\begin{array}{c}\text { Insolation } \\
\text { levels (W/ m}{ }^{2}\end{array}$} & \multicolumn{3}{c|}{ SMPPT } & \multicolumn{3}{c}{ DMPPT } \\
\hline $\mathrm{G}_{1}$ & $\mathrm{G}_{2}$ & $\mathrm{G}_{3}$ & $\begin{array}{c}\mathrm{P}_{\mathrm{PV}} \\
(\mathrm{W})\end{array}$ & $\begin{array}{c}\mathrm{P}_{\mathrm{o}} \\
(\mathrm{W})\end{array}$ & $\begin{array}{c}\eta_{\%} \\
(\%)\end{array}$ & $\begin{array}{c}\mathrm{P}_{\mathrm{PV}} \\
(\mathrm{W})\end{array}$ & $\begin{array}{c}\mathrm{P}_{\mathrm{o}} \\
(\mathrm{W})\end{array}$ & $\begin{array}{c}\eta \\
(\%)\end{array}$ \\
\hline 845 & 736 & 721 & 68.66 & 67.17 & 97.83 & 70.59 & 66.35 & 93.99 \\
625 & 736 & 571 & 46.02 & 44.74 & 97.22 & 48.03 & 44.56 & 92.78 \\
735 & 640 & 345 & 43.33 & 42.17 & 97.32 & 44.51 & 40.52 & 91.04 \\
645 & 420 & 305 & 23.59 & 22.67 & 96.10 & 24.95 & 22.47 & 90.06 \\
\hline 724 & 720 & 680 & 61.9 & 60.46 & 97.67 & 63.85 & 59.82 & 93.69 \\
\hline
\end{tabular}

The input and output powers of both SMPPT and DMPPT systems were measured directly using a single phase clamp on a power quality Fluke 345 clamp meter (Fluke Corporation, Everett, Washington, USA) for different shading patterns practically, and readings were tabulated with power conversion efficiency (Table 6).

Table 6 demonstrates that the efficiency of the SMPPT system was higher (around 4-5\%) than that of the DMPPT system. The losses in the DMPPT system are due to an increase in converter circuits which cause more switching and power conversion losses.

\section{Conclusions}

This work analyses the performance of ANNtrained MPPT controllers in a centralized and distributed environment. In the past, it has been inferred that a SMPPT controller was more efficient than a DMPPT controller. Even though a DMPPT harvests more power from the PV panel, the efficiency is reduced due to static and dynamic losses introduced by the converters. It must be kept in mind that a DMPPT controller increases the modularity, stability, and reliability. Hence, an MPPT controller for specific applications has to be preferred. This work 
suggests that a SMPPT controller is more appropriate for low power and non-critical loads like residential loads due to its low cost and high efficiency. In contrast, DMPPT controllers are preferred for critical loads like hospitals, where stability and reliability are of concern. This work can be extended to improve the performance of a DMPPT with interleaved soft switching converters.

\section{Acknowledgment}

The authors wish to thank the management of SSN College of Engineering, Chennai, India, for providing all the experimental and computational facilities to carry out this work through internal funding.

\section{References}

Ait Cheikh MS, Haddadi M, Zerguerras A (2007), Design of a neural network control scheme for the maximum power point tracking (MPPT). Revue des Energies Renouvelables 10(1):109118.

Al-Amoudi A, Zhang L (2000), Application of radial basis function networks for solar-array modeling and maximum power-point prediction. IEEE Proceeding - Generation, Transmission and Distribution 147(5):310-316.

De Medeiros Torres A, Antunes FLM, Dos Reis FS (1998), An artificial neural network-based real time maximum power tracking controller for connecting a PV System to the grid. Proceeding of IEEE the $24^{\text {th }}$ Annual Conference on Industrial Electronics Society 1:554-558.

Esram T, Chapman PL (2007), Comparison of photovoltaic array maximum power point tracking techniques. IEEE Transaction on Energy Conversion 22(2):439-449.

Femia N, Petrone G, Spagnuolo G, Vitelli M (2005), Optimization of perturb and observe maximum power point tracking method. IEEE Trans.Power Electron 20(4):963-973.

Herrmann W, Wiesner W, Waassen W (1997), Hot spots investigations on PV modules - new concepts for a test standard and consequences for module design with respect to by-pass diodes. Proceedings of the $26^{\text {th }}$ IEEE Photovoltaic Specialists Conference 1129-1132.
Hiyama T, Kitabayashi K (1997), Neural network based estimation of maximum power generation from PV module using environment information. IEEE Transaction on Energy Conversion 12(3):241-247.

Jain S, Agarwal V (2004), A new algorithm for rapid tracking of approximate maximum power point in photovoltaic systems. IEEE Power Electron. Lett. 2(1):16-19.

Jiang YC, Jaber A, Qahouq A, Orabi M (2012), AC PV solar system distributed architecture with maximum power point tracking. IEEE Telecommunication Energy Conference 1-5.

Jordan D, Kurtz SR (2012), Photovoltaic degradation rates-An analytical review. NREL Report Number JA-5200-51664.

Karatepe E, Boztepe M, Colak M (2007), Development of suitable model for characterizing photovoltaic arrays with shaded solar cells. Solar Energy 81(8):977-992.

Kasper M, Bortis D, Kolar JW (2014), Classification and comparative evaluation of PV panel-integrated DC-DC converter concepts. IEEE Transactions on Power Electronics 29(5):2511-2526.

Kazutaka I (2012), New I-V characteristics scantype MPPT control method for PV generation system. Journal of Technology Innovations in Renewable Energy 1:87-91.

Koutroulis E, Kalaitzakis K, Voulgaris NC (2001), Development of a microcontroller-based, photovoltaic maximum power point tracking control system. IEEE Trans Power Electron 16(1):46-54.

Masoum MAS, Dehbonei H, Fuchs EF (2002), Theoretical and experimental analyses of photovoltaic systems with voltage- and current-based maximum power-point tracking. IEEE Transactions on Energy Conversion 17(4):514-522.

Patel H, Agarwal V (2008), Matlab-based modeling to study the effects of partial shading on PV array characteristics. IEEE Trans Energy Conversion 55(4):1689-1698.

Ramaprabha R, Mathur BL (2008), Modeling and simulation of solar PV array under partial shaded conditions. Proc. of IEEE Int. Conf. on Sustainable Energy Technologies 12-16.

Ramaprabha R, Mathur BL (2012), A comprehensive review and analysis of solar photovoltaic array configurations under partial shaded conditions. International Journal of 
Photo energy, Special Issue on Recent Developments in Solar Energy Harvesting and Photo Catalysis 1-16.

Silvestre S, Boronat A, Chouder A (2009), Study of bypass diodes configuration on PV modules, Applied Energy 86(9):1632-1640.

Villalva MG, Gazoli JR, Filho ER (2009), Comprehensive approach to modeling and simulation of photovoltaic arrays. IEEE Transactions on Power Electronics 24(5):11981208.
Walker GR, Pierce JC (2006), Photovoltaic DCDC module integrated converter for novel cascaded and bypass grid connection topologies design and optimization, IEEE Power Electronics Specialists Conference 1-7.

Walker GR, Semia PC (2004), Cascaded DC-DC converter connection of photovoltaic modules. IEEE Transactions on Power Electronics 19(4):1130-1139.

Walker GS (2001), Evaluating MPPT converter topologies using a MATLAB PV Model. Journal of Electrical \& Electronics Engineering, Australia 21(1):49-56. 